\title{
Rapid Activation of Antioxidant Defenses by Nerve Growth Factor Suppresses Reactive Oxygen Species during Neuronal Apoptosis: Evidence for a Role in Cytochrome $c$ Redistribution
}

\author{
Rebecca A. Kirkland, Geraldine M. Saavedra, and James L. Franklin \\ Department of Pharmaceutical and Biomedical Sciences, The University of Georgia College of Pharmacy, Athens, Georgia 30602
}

\begin{abstract}
Depriving mouse sympathetic neurons of nerve growth factor (NGF) causes their apoptotic death. A Bax-dependent increase of mitochondrial-derived reactive oxygen species (ROS) begins in these cells soon after NGF withdrawal. We investigated the effects on these ROS of adding NGF to cultures of NGF-deprived neurons. ROS levels were monitored with the fluorescent, redox-sensitive dyes CM$\mathrm{H}_{2}$ DCFDA and MitoSOX Red. The intensity of the former dye increases when it is oxidized by $\mathrm{H}_{2} \mathrm{O}_{2}$ and free radicals downstream of $\mathrm{H}_{2} \mathrm{O}_{2}$. MitoSOX Red is relatively insensitive to oxidation by $\mathrm{H}_{2} \mathrm{O}_{2}$ but is sensitive to oxidation by superoxide $\left(\mathrm{O}_{2}{ }^{-}\right)$. Withdrawing NGF increased CM- $\mathrm{H}_{2}$ DCFDA intensity, indicating elevated $\mathrm{H}_{2} \mathrm{O}_{2}$-associated ROS. Re-exposure of cells deprived of NGF to NGF resulted in rapid suppression of these ROS. Neurons deprived of NGF also had increased MitoSOX Red intensities. Readdition of NGF had no effect on MitoSOX Red fluorescence. The suppression of CM- $\mathrm{H}_{2}$ DCFDA-detected ROS by NGF was caused by a rapid activation of glutathione redox cycling. The most likely explanation for these findings is that mitochondria increased $\mathrm{O}_{2}{ }^{--}$production after NGF withdrawal. The $\mathrm{O}_{2}{ }^{-{ }^{-}}$was converted to $\mathrm{H}_{2} \mathrm{O}_{2}$ by dismutation, and the $\mathrm{H}_{2} \mathrm{O}_{2}$ was detoxified by accelerated glutathione redox cycling. Our previous work shows that $\mathrm{H}_{2} \mathrm{O}_{2}$ induces cytochrome $c$ to be released from mitochondria in NGF-supported sympathetic neurons, whereas antioxidants that detoxify $\mathrm{H}_{2} \mathrm{O}_{2}$ block cytochrome $c$ redistribution in NGF-deprived neurons. Readdition of NGF also immediately inhibits cytochrome $c$ release. We present evidence that this inhibition is mediated by the rapid activation of glutathione redox cycling by NGF.
\end{abstract}

Key words: apoptosis; reactive oxygen; mitochondria; nerve growth factor; cell death; glutathione

\section{Introduction}

Approximately $50 \%$ of the neurons generated during vertebrate neurogenesis die by apoptosis in a process thought to be important for sculpting the developing nervous system (Oppenheim, 1991; Yuan and Yanker, 2001). Neurotrophins excreted by target or other tissues are the major determinants of which neurons survive the period of developmental death. Those cells obtaining sufficient quantities of an appropriate neurotrophin survive and live into the adulthood of the organism, whereas those that do not execute the apoptotic program and are removed by phagocytic cells (Danial and Korsmeyer, 2004). The prototypical model for investigating the cellular and molecular mechanisms underlying this death consists of rodent sympathetic neurons dissociated from late embryonic or early postnatal rats or mice and grown in cell culture. Sympathetic neurons of this age require the neurotrophin nerve growth factor (NGF) to live. Depriving these cells of NGF causes their apoptotic death both in vivo and in vitro.

\footnotetext{
Received Feb. 27, 2007; revised Aug. 7, 2007; accepted Aug. 30, 2007.

This work was supported by National Institutes of Health Grant NS37110.

Correspondence should be addressed to James L. Franklin, Department of Pharmaceutical and Biomedical Sciences, The University of Georgia College of Pharmacy, 357 Wilson Pharmacy, Athens, GA 30602. E-mail: jfrankli@rx.uga.edu.

DOI:10.1523/JNEUROSCI.3590-07.2007

Copyright $\odot 2007$ Society for Neuroscience $\quad$ 0270-6474/07/2711315-12\$15.00/0
}

NGF withdrawal induces apoptosis in sympathetic neurons by causing the pro-apoptotic protein, Bax, to bind to the outer mitochondrial membrane where it induces release of cytochrome $c$ from the mitochondrial intermembrane space into the cytoplasm (Putcha et al., 1999). Other apoptogenic substances may also be released (Susin et al., 1999; Du et al., 2000; Li et al., 2001). The cytosolic cytochrome $c$ stimulates formation of the apoptosome and activation of caspase proteases, the effectors of apoptotic death (Liu et al., 1996; Li et al., 1997; Zou et al., 1997). Increased levels of reactive oxygen species (ROS) occur in these neurons long before any cells become committed to die. These ROS lie downstream of Bax, derive from the mitochondrial electron transport chain, and appear to be an important component of the mechanism by which Bax causes cytochrome $c$ release (Kirkland and Franklin, 2001; Kirkland et al., 2002a,b).

The intensity of the fluorescent redox-sensitive dye, dihydrorhodamine 123, increases in NGF-deprived rat sympathetic neurons and GT1-trk cells in culture, indicating that it has become oxidized by the elevated levels of ROS in those cells (Dugan et al., 1997). Readdition of NGF to these cultures inhibits further increases in dye intensity, suggesting that NGF acutely suppresses ROS. The mechanism underlying this suppression is unknown. Possibilities include NGF-induced inhibition of mitochondrial ROS production, rapid activation of cellular antioxidant defenses 
by NGF, or both. We used two redox-sensitive dyes to investigate the underlying mechanism, one that primarily detects $\mathrm{H}_{2} \mathrm{O}_{2}$ and $\mathrm{H}_{2} \mathrm{O}_{2}$-produced ROS and the other that primarily detects $\mathrm{O}_{2}{ }^{--}$. NGF readdition did not suppress mitochondrial $\mathrm{O}_{2}{ }^{--}$production. Rather, it detoxified $\mathrm{H}_{2} \mathrm{O}_{2}$ and $\mathrm{H}_{2} \mathrm{O}_{2}$-produced ROS by activating the principal antioxidant mechanism for removal of $\mathrm{H}_{2} \mathrm{O}_{2}$ from cells, the glutathione redox cycling pathway. We provide evidence that the rapid suppression of ROS by NGF is at least partially responsible for the concurrent NGF-mediated block of cytochrome $c$ redistribution from mitochondria.

\section{Materials and Methods}

Reagents. Monochlorobimane, 5-(and-6)-chloromethyl-2', 7'dichlorodihydrofluorescein diacetate $\left(\mathrm{CM}-\mathrm{H}_{2} \mathrm{DCFDA}\right)$, MitoTracker Green, and MitoSOX Red were purchased from Invitrogen (Eugene, OR). Nerve growth factor $2.5 \mathrm{~S}$ was purchased from Harlan Bioproducts (Indianapolis, IN). All other reagents were purchased from Sigma (St. Louis, MO) unless otherwise stated.

Cell culture. Superior cervical ganglia were dissected from wild-type $\mathrm{C} 57 \mathrm{Bl} / 6$ mouse pups on the first day after birth. Neurons were enzymatically and mechanically dissociated from the ganglia as described previously (Martin et al., 1988; Franklin et al., 1995; Deckwerth et al., 1996; Kirkland et al., 2002b). Cells from $1 / 2$ ganglion were plated onto an ammoniated collagen substrate on \# 1 glass coverslips for microscopy experiments. The coverslips were placed in $35 \mathrm{~mm}$ Costar tissue culture dishes (Corning, Corning, NY) and incubated in culture medium consisting of Eagle's minimum essential medium with Earle's salts (Invitrogen, Carlsbad, CA) supplemented with $10 \%$ fetal bovine serum, $100 \mathrm{U} / \mathrm{ml}$ penicillin, $100 \mu \mathrm{g} / \mathrm{ml}$ streptomycin, $20 \mu \mathrm{M}$ fluorodeoxyuridine, $20 \mu \mathrm{M}$ uridine, $1.4 \mathrm{~mm}$ L-glutamine, and $50 \mathrm{ng} / \mathrm{ml}$ 2.5S NGF. Cells from 1.5 ganglia were plated onto collagenized $35 \mathrm{~mm}$ tissue culture dishes for immunoblot experiments. All cultures were maintained in the above medium at $35^{\circ} \mathrm{C}$ in an incubator having an atmosphere of $95 \%$ air and $5 \% \mathrm{CO}_{2}$.

Nerve growth factor was withdrawn from cultures by incubating them in standard culture medium containing NGF-neutralizing antibodies (Abcam, Cambridge, MA or Cedarlane Labs, Burlington, Ontario) (Franklin and Johnson, 1998) and lacking NGF. Experiments were begun when neurons had been in culture for 6-9 d. All data in figures are from experiments done with neurons from at least three separate platings.

Confocal and fluorescence microscopy. A Nikon (Melville, NY) C1 laserscanning confocal microscope mounted on a Nikon Eclipse TE 300 inverted microscope was used for all confocal microscopy. The confocal microscope was controlled by EZC1 software running on a Dell computer. Neurons, observed with a $60 \times$ plan oil immersion lens (numerical aperture, 1.4), were chosen at random and scanned by the confocal microscope. Laser power, confocal pinhole size, and photomultiplier gain were maintained at constant levels during an experiment.

Fluorescence microscopy was done with a Nikon Eclipse TE 300 microscope. Cells were observed with a $20 \times$ objective. Light was provided by a xenon lamp and images collected by a cooled CCD camera (MicroMax; Princeton Instruments, Trenton, NJ). Filters were changed by a Lambda 10-2 optical filter changer (Sutter Instruments, Novato, CA). All images were quantified by measuring the raw pixel intensities in the cytoplasm of neuronal somas with the region tool of MetaMorph software (Universal Imaging, West Chester, PA). The area quantified covered a $60 \mu \mathrm{m}^{2}$ area of cytoplasm in confocal microscopy images and a 33 $\mu \mathrm{m}^{2}$ area in fluorescence microscopy images. The intensity of each neuron was normalized to that of NGF-maintained neurons receiving the same concentration of dye for the same time as the experimental cells. Normalized data are shown as fold change from the intensity of the dye measured in sibling cultures of neurons maintained since the time of plating in NGF-containing medium. All microscopy was done at room temperature.

ROS measurement. $\mathrm{H}_{2} \mathrm{O}_{2}$-associated ROS were detected using the redox-sensitive dye $\mathrm{CM}-\mathrm{H}_{2} \mathrm{DCFDA}$. This dye is membrane permeant and is trapped in cells by binding of the chloromethyl group to cellular thiols. It is almost nonfluorescent in its reduced form but becomes intensely fluorescent after oxidation by $\mathrm{H}_{2} \mathrm{O}_{2}$ and ROS downstream of
$\mathrm{H}_{2} \mathrm{O}_{2}$ (Royall and Ischiropoulos, 1993). We extensively characterized the use of this dye in rat and mouse sympathetic neurons (Kirkland and Franklin, 2001; Kirkland et al., 2002b). This characterization shows that when $\mathrm{CM}-\mathrm{H}_{2}$ DCFDA is trapped in these cells, it is insensitive to $\mathrm{pH}$ changes within the physiological range and is not photo-oxidized at the laser power used in our experiments. We found equal loading of CM$\mathrm{H}_{2}$ DCFDA in cells receiving the experimental treatments reported in this study (data not shown). Cultures were incubated in the appropriate experimental medium containing $\mathrm{CM}-\mathrm{H}_{2}$ DCFDA $(10 \mu \mathrm{M})$ for $20 \mathrm{~min}$ at $35^{\circ} \mathrm{C}$. They were then washed twice with Leibovitz's L-15 medium containing the experimental treatments and left in the last wash for confocal microscopy. CM- $\mathrm{H}_{2}$ DCFDA was excited with the $488 \mathrm{~nm}$ line of the confocal laser. The green photomultiplier channel of the confocal microscope was used for image acquisition.

We used MitoSOX Red to determine relative $\mathrm{O}_{2}{ }^{-{ }^{-}}$levels. MitoSOX is a new redox-sensitive dye that is composed of hydroethidine linked by a hexyl carbon chain to a triphenylphosphonium group. The triphenylphosphonium cation targets the molecule to the mitochondrial matrix because of the negative membrane potential across the inner mitochondrial membrane (Robinson et al., 2006). Oxidation of the hydroethidine moiety by $\mathrm{O}_{2}^{--}$generates 2 -hydroxyethidium, which becomes intensely fluorescent after intercalation into mitochondrial DNA (Ross et al., 2005; Zhao et al., 2003, 2005). MitoSOX can also be oxidized by ROS other than $\mathrm{O}_{2}{ }^{--}$but is most sensitive to oxidation by $\mathrm{O}_{2}{ }^{-{ }^{-}}$. Cultures were incubated for $10 \mathrm{~min}$ at $35^{\circ} \mathrm{C}$ in the appropriate experimental medium containing MitoSOX $(2 \mu \mathrm{M})$. This time and concentration were chosen as optimal for the experiments conducted in this study. Dye intensity was measured only in the cytoplasm. Nuclear staining occurred only in a small proportion of apoptotic cells that appeared to have compromised plasma membranes. Neurons in which cytoplasm could not be clearly differentiated from the nucleus were excluded from analysis. Supplemental Figure 1 shows that MitoSOX intensity increased at a linear rate in NGF-deprived neurons with up to $40 \mathrm{~min}$ of exposure (Johnson et al., 2007). After incubation in MitoSOX, cultures were washed twice with L-15 medium and kept in the second wash for microscopy. MitoSOX was excited with the $408 \mathrm{~nm}$ line of the confocal laser (Robinson et al., 2006), and the red photomultiplier channel of the confocal microscope was used for image acquisition. Although longer wavelengths (e.g., 488, 543) can also excite MitoSOX, the violet excitation is far more selective for the MitoSOX $/ \mathrm{O}_{2}^{--}$product than are the longer wavelengths.

Glutathione assay. Relative glutathione (GSH) levels were determined with monochlorobimane (MCB). MCB becomes intensely fluorescent when it is enzymatically bound to GSH (Fernandez-Checa and Kaplowitz, 1990). Cultures were incubated in appropriate experimental medium containing $\mathrm{MCB}$ for $20 \mathrm{~min}$ at $35^{\circ} \mathrm{C}$ in a $5 \% \mathrm{CO}_{2}$ atmosphere. Cultures were washed once with L-15 medium for fluorescence microscopy. The dye was excited at $380 \pm 15 \mathrm{~nm}$. The emission filter was $510 \pm 20 \mathrm{~nm}$. Only neurons that were clearly separate from other cells (i.e., not lying on top of others) were used for quantification of MCB intensity.

Immunocytochemistry and immunoblotting. Immunocytochemical staining for cytochrome $c$ was done as described previously (Deshmukh and Johnson, 1998; Putcha et al., 1999; Kirkland and Franklin, 2001; Kirkland et al., 2002b). Anti-cytochrome $c$ monoclonal antibody (clone 6H2.B4) was obtained from PharMingen (San Diego, CA) or Promega (Madison, WI). The secondary antibody was an Alexa Fluor-conjugated anti-mouse antibody obtained from Invitrogen.

Western blotting for cytochrome $c$ and $\beta$-tubulin III was done as described previously (Kirkland and Franklin, 2001; Kirkland et al., 2002b). Proteins from cell lysates were separated by gel electrophoresis (10 or $12 \%$ Tris- $\mathrm{HCl}$ precast gels; Bio-Rad, Hercules, CA, or Life Gels, Clarkston, GA) and transferred onto polyvinylidene fluoride membranes (Millipore, Bedford, MA). Membranes were then incubated in $0.5 \mu \mathrm{g} / \mathrm{ml}$ mouse cytochrome $c$ antibody (Clone 7H8.2C12; PharMingen) or anti- $\beta$ tubulin III antibody at a 1:1000 dilution. The secondary antibody, used at a dilution of 1:1000 to 1:4000), was provided with ECL kits (GE Healthcare, Arlington Heights, IL). Blot documentation and analysis was done with a Fotodyne Foto/Analyst Dual-Light Luminary Workstation running TotalLab Software (Fotodyne, Hartland, WI).

Statistics. Statistical analysis was done with SigmaStat 2.0 (Systat Soft- 
ware, San Jose, CA). Appropriate statistical measures were determined for each experiment based on distribution of data. The statistics used are indicated in the figure legends or text. All ANOVAs are Kruskal-Wallis one-way ANOVA on ranks followed by Dunn's multiple comparisons post hoc test. Differences were considered significant if $p$ was $<0.01$. All error bars are \pm SEM. Graphs were prepared with SigmaPlot 9.0 (Systat Software)

\section{Results}

\section{NGF readdition rapidly suppressed $\mathrm{H}_{2} \mathrm{O}_{2}$-associated $\mathrm{ROS}$ in} NGF-deprived mouse sympathetic neurons

To explore the mechanisms mediating the suppression of ROS by NGF, we first used the fluorescent redox-sensitive dye CM$\mathrm{H}_{2}$ DCFDA. This dye has several features that make it superior to dihydrorhodamine 123 for ROS detection (Kirkland and Franklin, 2001). Previous work has demonstrated that, as with dihydrorhodamine, the fluorescence intensity of CM- $\mathrm{H}_{2}$ DCFDA and related redox-sensitive dyes increases in rat and mouse sympathetic neurons when they are deprived of NGF (Greenlund et al., 1995; Kirkland and Franklin, 2001; Kirkland et al., 2002b; Kirkland and Franklin, 2003). Figure 1, $A$ and $B$, shows that depriving mouse sympathetic neurons in cell culture of NGF for $24 \mathrm{~h}$ caused a approximately fivefold increase in CM- $\mathrm{H}_{2}$ DCFDA fluorescence intensity, indicating that ROS levels had increased in them. Readdition of NGF to the culture medium during the 20 min period of dye loading suppressed $\sim 80 \%$ of this increase. Therefore, NGF readdition suppresses $\mathrm{CM}-\mathrm{H}_{2} \mathrm{DCFDA}$ intensity in NGF-deprived mouse sympathetic neurons in a manner similar to that observed when dihydrorhodamine 123 was used as the ROS indicator for NGF-deprived rat sympathetic neurons (Dugan et al., 1997). As reported previously (Kirkland et al., 2002a), maintaining the NGF-deprived neurons from the time of deprivation in culture medium containing the broad-spectrum caspase inhibitor boc-aspartyl(OMe)-fluoromethylketone (BAF) suppressed $\sim 80 \%$ of the increase in dye intensity. This finding suggests a role for caspases in ROS production in NGF-deprived sympathetic neurons similar to that described in other cell types (Tan et al., 1998; Ricci et al., 2003, 2004). This concentration of BAF also prevents all of the cells from dying over this period (Deshmukh et al., 1996, 2000; Kirkland et al., 2002b). Readdition of NGF to BAF-maintained cultures during the period of dye loading suppressed CM- $\mathrm{H}_{2}$ DCFDA intensity to near the baseline levels found in neurons maintained from the time of plating in NGF-containing medium. Neurons deprived of NGF and maintained alive for $48 \mathrm{~h}$ in BAF-containing medium (Kirkland et al., 2002b) had CM- $\mathrm{H}_{2}$ DCFDA intensities similar to those of cells maintained for $24 \mathrm{~h}$ in BAF-containing medium without NGF. However, readdition of NGF took longer to suppress ROS in these cells than in cultures deprived of NGF for only $24 \mathrm{~h}$. Therefore, NGF suppressed both the BAF-sensitive and BAFinsensitive components of the ROS increase. None of the differences in $\mathrm{CM}-\mathrm{H}_{2}$ DCFDA intensities in cells receiving the various treatments can be explained by differential dye loading as cells treated with all the conditions reported in this manuscript load with the same amount of dye (Kirkland et al., 2002b) (data not shown).

Figure $1 C$ shows that the suppressant effect of NGF on CM$\mathrm{H}_{2}$ DCFDA fluorescence intensity was not caused by reduction of the oxidized dye to the nonfluorescent form. NGF-deprived cells were loaded with $\mathrm{CM}-\mathrm{H}_{2}$ DCFDA and re-exposed to NGF after the dye had become oxidized (Fig. $1 C$ ). This treatment did not cause a significant decrease in dye intensity ( $p>0.3$ by ANOVA). Therefore, the rapid suppression of CM- $\mathrm{H}_{2}$ DCFDA intensity by
NGF readdition was not caused by a re-reduction of the dye but, rather, by a rapid suppression of the ROS detected by the dye.

Mouse sympathetic neurons that have been maintained in culture medium containing NGF from the time of plating (6-9d) do not show a significant rise in ROS levels until $\sim 6 \mathrm{~h}$ after NGF withdrawal. Peak ROS levels are reached at $18 \mathrm{~h}$ and later times after deprivation (Kirkland et al., 2002b). To determine how fast ROS levels recovered after having been suppressed by NGF readdition, cultures were deprived of NGF for $24 \mathrm{~h}$ and then reexposed to it for varying periods before a second deprivation during $\mathrm{CM}-\mathrm{H}_{2} \mathrm{DCFDA}$ loading. Figure $1 \mathrm{D}$ shows that longer exposures to NGF led to longer periods for return of ROS to the elevated levels found in cells not re-exposed to it. Neurons treated with NGF for 5 min and subsequently deprived of it during dye loading had $\sim 80 \%$ of the $\mathrm{CM}-\mathrm{H}_{2}$ DCFDA intensity found in NGF-deprived cells not pretreated with NGF. Twenty minutes of pretreatment with NGF before subsequent deprivation during the period of dye loading resulted in an average CM- $\mathrm{H}_{2}$ DCFDA intensity $\sim 40 \%$ of that found in the cells not re-exposed to NGF. A similar time course for recovery of ROS levels was apparent in NGF-pretreated neurons that had been deprived of NGF in the presence of BAF. These data suggest that the mechanism for suppression of ROS by NGF is rapidly activated and that this activation becomes more persistent with longer periods of NGF re-exposure.

A principal source of ROS in most cells is mitochondrial respiration. Electrons leaking from the mitochondrial electron transport chain reduce $\mathrm{O}_{2}$ to the free radical ROS, superoxide $\left(\mathrm{O}_{2}{ }^{--}\right)$(Turrens, 1997; Cai and Jones, 1998; Halliwell and Gutteridge, 1999; Nicholls and Budd, 2000; Nicholls and Ward, 2000; Nicholls and Ferguson, 2002). The increased ROS in NGFdeprived mouse and rat sympathetic neurons appear to derive, for the most part, from the respiratory chain as they are potently inhibited by mitochondrial respiratory inhibitors and protonophores (Dugan et al., 1997; Kirkland and Franklin, 2001; Kirkland et al., 2002b). Activated caspases are known to increase mitochondrial ROS production in several cell types by attacking the $\mathrm{NADH}$ dehydrogenase $\mathrm{Fe}-\mathrm{S}$ protein 1 subunit of the first respiratory complex (Ricci et al., 2003, 2004). Profound suppression of ROS in NGF-deprived neurons by inclusion of BAF in the culture medium suggests that caspases are also involved in production of ROS in these cells. However, even with BAF treatment, ROS remained elevated in NGF-deprived cells, suggesting that other mechanisms also contributed to the increased ROS. One such possible mechanism is Bax-dependent depletion of cytochrome $c$ from the electron transport chain (Starkov et al., 2002). Removal of cytochrome $c$ from the chain can increase leakage of electrons to $\mathrm{O}_{2}$, elevating the rate of production of $\mathrm{O}_{2}{ }^{--}$. To determine whether suppression of the residual ROS remaining in BAF-saved neurons by NGF reintroduction (Fig. $1 B$ ) was caused by repletion of cytochrome $c$ to the electron transport chain, we deprived cultures of NGF and maintained them in BAFcontaining medium for $24-48 \mathrm{~h}$, followed by immunoblotting for cytochrome $c$. Because of the rapid degradation of cytochrome $c$ when it is released into the cytoplasm of NGF-deprived mouse sympathetic neurons, there is no cytoplasmic cytochrome $c$ to be detected in cytosolic fractions from them at any time after its release from mitochondria (Putcha et al., 2000). The only immunoblot-detectable cytochrome $c$ remaining in these cells is mitochondrial. Therefore, the total cellular levels of cytochrome $c$ detected by immunoblotting in NGF-deprived cells should reflect only the cytochrome $c$ left in mitochondria (Xie et al., 2005). Although this technique might not be ideal for a definitive deter- 

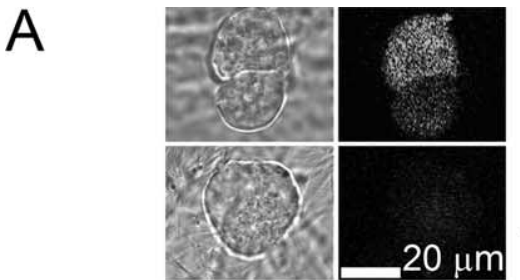

-NGF (24 hr)

$-\mathrm{NGF}(24 \mathrm{hr})$ $+\mathrm{NGF}(20 \mathrm{~min})$

\section{$\mathrm{B}$}

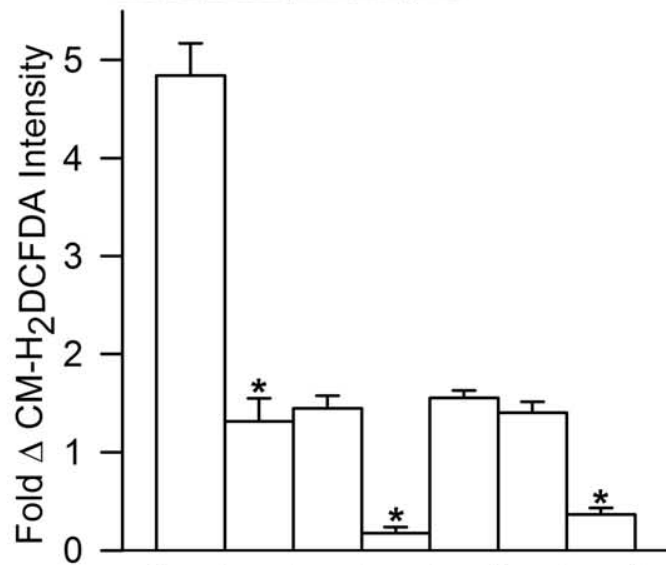

D

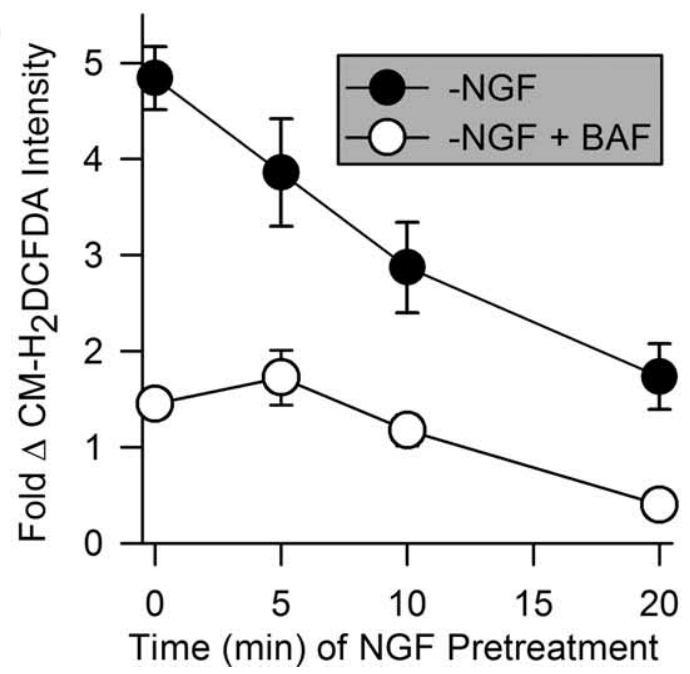

Figure 1. Elevated levels of ROS in NGF-deprived mouse sympathetic neurons in cell culture were rapidly suppressed by re-exposure to NGF. $A$, Paired phase and confocal micrographs of neurons loaded with the redox-sensitive dye $\mathrm{CM}_{2} \mathrm{H}_{2} \mathrm{DCFDA}$. By $24 \mathrm{~h}$ after NGF withdrawal, CM- $\mathrm{H}_{2} \mathrm{DCFDA}$ intensity had increased, indicating that the dye was oxidized by ROS. Reintroduc- mination of the actual rate of release of cytochrome $c$ from mitochondria, it is more than adequate for determining whether there is an increase in cytochrome $c$ after NGF readdition. Figure 2, A and $B$, shows that withdrawal of NGF caused a $\sim 60 \%$ loss of cytochrome $c$ from these cultures. Reintroduction of NGF had no effect on cytochrome $c$ levels during the period in which it caused rapid suppression of ROS levels. Similarly, acute application of NGF to NGF-deprived cultures not supported by BAF did not affect the reduced cytochrome $c$ levels in them (data not shown). Therefore, repletion of cytochrome $c$ to the electron transport chain by NGF readdition was not the mechanism by which NGF caused suppression of ROS in NGF-deprived neurons.

\section{$\mathrm{O}_{2} \cdot-$ levels were not suppressed by NGF readdition}

Most ROS in NGF-deprived sympathetic neurons appear to derive from the electron transport chain (Dugan et al., 1997; Kirkland and Franklin, 2001; Kirkland et al., 2002b). Therefore, an obvious mechanism for suppression of ROS by NGF readdition is through an effect on mitochondrial ROS production. NGF could, for example, suppress ROS by decreasing the rate of leakage of electrons from the chain. CM- $\mathrm{H}_{2}$ DCFDA is oxidized by $\mathrm{H}_{2} \mathrm{O}_{2}$ and other ROS lying downstream from dismutation of $\mathrm{O}_{2}{ }^{-}$. It is relatively insensitive to oxidation by $\mathrm{O}_{2} \cdot$ - (Royall and Ischiropoulos, 1993; Kirkland and Franklin, 2001; Kirkland et al., 2002b). Therefore, this dye allows only an indirect measure for $\mathrm{O}_{2}-$ - production by mitochondria and cannot give a definitive answer as to whether NGF blocks production of mitochondrial $\mathrm{O}_{2}{ }^{--}$or acts to suppress ROS lying downstream of $\mathrm{O}_{2}^{--}$dismutation (e.g., $\left.\mathrm{H}_{2} \mathrm{O}_{2}, \mathrm{OH}^{--}\right)$. MitoSOX Red is a new redox-sensitive dye that is targeted to mitochondria and is more sensitive to oxidation by $\mathrm{O}_{2}{ }^{--}$than many other ROS species, including $\mathrm{H}_{2} \mathrm{O}_{2}$ (Zhao et al., 2003, 2005; Ross et al., 2005; Robinson et al., 2006). Figure $3 \mathrm{~A}$ shows that the mitochondria of NGF-deprived neurons were intensely stained by MitoSox. Figure $3 B$ shows the effect of treating neurons exposed to MitoSox in the culture medium with 2-methylnaphthalene-1,4-dione (menadione), a plasma membrane-permeant compound that generates $\mathrm{O}_{2}{ }^{--}$intracellularly by mediating transfer of electrons from nicotinamide adenine dinucleotide phosphate or NADPH to $\mathrm{O}_{2}$ in a redox cycling

\footnotetext{
$\leftarrow$

tion of NGF during the 20 min period of $C M-H_{2}$ DCFDA loading inhibited this oxidation. $B$, Effects on neuronal $\mathrm{CM}-\mathrm{H}_{2} \mathrm{DCFDA}$ intensity of NGF readdition to cultures deprived of NGF for $24-48 \mathrm{~h}$. Because of ongoing apoptotic death, all of the cells deprived of NGF for the longer period were maintained alive by adding the broad-spectrum caspase inhibitor BAF $(50 \mu \mathrm{m})$ to the culture medium at the time of NGF withdrawal. Note that the caspase inhibitor also potently suppressed ROS (e.g., CM-H H $_{2}$ CFDA intensity) (Kirkland et al., 2002a,b). For neurons deprived of NGF for $24 \mathrm{~h}$, NGF readdition was done during the $20 \mathrm{~min}$ period of $\mathrm{CM}-\mathrm{H}_{2}$ DCFDA loading. The $48 \mathrm{~h}$ BAF-supported neurons were re-exposed to NGF either during the 20 min dye-loading period or for $100 \mathrm{~min}$ before dye loading plus the $20 \mathrm{~min}$ of dye loading. Stars indicate a significant difference ( $p<0.001$ by ANOVA) from the same condition with no readdition of NGF during the period of $\mathrm{CM}_{2} \mathrm{H}_{2} \mathrm{DCFDA}$ loading. $n=62-588$ neurons. $C$, NGF readdition did not suppress $\mathrm{CM}-\mathrm{H}_{2} \mathrm{DCFDA}$ intensity in NGF-deprived neurons by reducing the dye after it had become oxidized. Cultures deprived of NGF for $24 \mathrm{~h}$ were loaded with $\mathrm{CM}_{2} \mathrm{H}_{2} \mathrm{DCFDA}$ for $20 \mathrm{~min}$. The first bar is control $\mathrm{CM}_{-} \mathrm{H}_{2} \mathrm{DCFDA}$ intensity at the end of the 20 min load. For the other two conditions, the dye was washed out after the 20 min load either with medium containing NGF or lacking NGF. Dye intensity was then determined 20 min later. $n=126-522$ neurons. $D$, Time course of recovery of elevated ROS after NGF readdition followed by subsequent withdrawal. ROS recovered more slowly when NGF was again withdrawn after longer periods of NGF readdition. Neurons deprived of NGF for $24 \mathrm{~h}$ ( $\pm 50 \mu \mathrm{m}$ BAF) were exposed to NGF for various times before being loaded with $\mathrm{CM}-\mathrm{H}_{2}$ DCFDA for 20 min in medium containing no NGF and a NGFneutralizing antibody. Fold change shown in this and subsequent figures is change from the intensity of the dye measured in sibling cultures of neurons maintained since the time of plating in NGF-containing medium. $n=104-350$ neurons.
} 

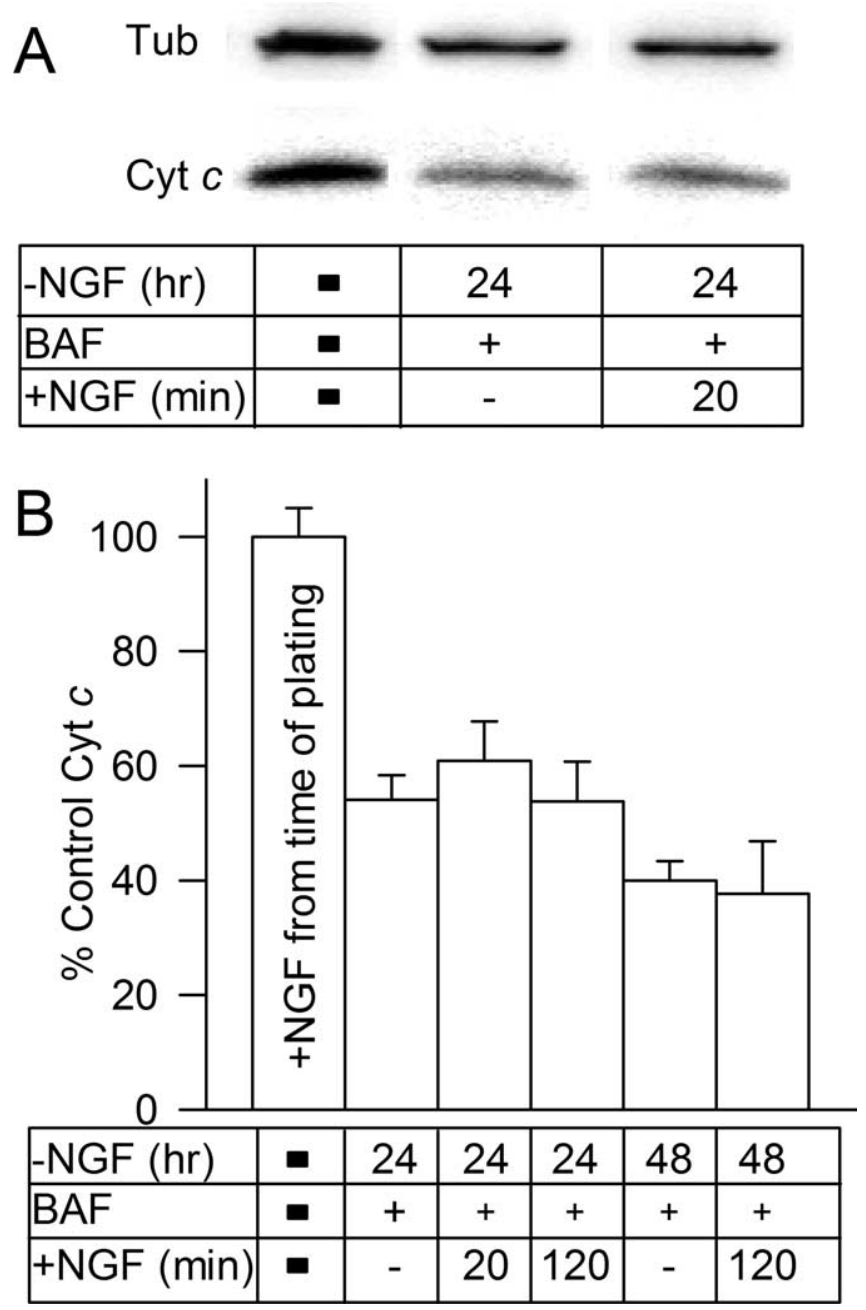

Figure 2. Readdition of NGF to NGF-deprived neurons did not reduce ROS levels in BAFmaintained neurons by causing repletion of mitochondrial cytochrome $c$ to the electron transport chain. $\boldsymbol{A}$, Western blots showing cytochrome c (Cyt c) levels in sibling cultures of NGFreplete and -deprived neurons. Loading control is $\beta$ - tubulin III (Tub) from the same cultures. Note the decrease in cytochrome c concentration after NGF withdrawal and the lack of an increase after NGF readdition. NGF-deprived cultures were maintained in BAF (50 $\mu \mathrm{m})$ containing medium for $24 \mathrm{~h}$ before immunoblotting. $\boldsymbol{B}$, Readdition of NGF to BAF (50 $\mu \mathrm{m})$ maintained cultures depleted of cytochrome $c$ by 24 or $48 \mathrm{~h}$ of NGF withdrawal did not increase cytochrome c levels within $2 \mathrm{~h}$ of readdition. $p>0.05$ by ANOVA for the $24 \mathrm{~h}$ treatments, and $p>0.8$ by $t$ test for the $48 \mathrm{~h}$ treatments. Cytochrome c concentration (density of bands) was determined by immunoblotting. Cytochrome $c$ was normalized to the amount of cytochrome $c$ found in sibling cultures maintained since the time of plating in medium containing NGF. Equal loading was assured by using sibling cultures plated at the same density, by determining amount of $\beta$-tubulin III in the cultures and by monitoring a nonspecific band recognized by the cytochrome c antibody (Xie et al., 2005). $n=5-38$ cultures.

process (Thor et al., 1982; Gutierrez, 2000). This treatment caused a $\sim 0.74$-fold increase in MitoSOX fluorescence intensity, whereas a concentration of $\mathrm{H}_{2} \mathrm{O}_{2}$ that causes a large increase in CM- $\mathrm{H}_{2}$ DCFDA fluorescence intensity had no effect (Kirkland et al., 2002b). These findings suggest that MitoSOX is an effective tool for investigating production of $\mathrm{O}_{2} \cdot$ - by the mitochondria of sympathetic neurons without the data being contaminated by significant interference from $\mathrm{H}_{2} \mathrm{O}_{2}$-associated ROS. The fluorescence intensity of MitoSOX in NGF-replete cells was very low. Withdrawing NGF caused an increase in MitoSOX intensity over a time course that was similar to that for the increase in CM$\mathrm{H}_{2}$ DCFDA intensity in NGF-deprived cells (Fig. $3 \mathrm{~A}, \mathrm{C}$ ) (Kirkland et al., 2002b). BAF suppressed the increase in MitoSOX intensity but did not prevent a partial rise. Both the mitochondrial uncoupler carbonyl cyanide p-trifluoromethoxyphenylhydrazone (FCCP) and rotenone, an inhibitor of electron flow through respiratory complex I, greatly suppressed the increase of MitoSOX intensity in NGF-deprived neurons. These compounds also suppressed the increase in intensity of MitoSOX fluorescence in NGF-deprived, BAF-maintained cells (Fig. 3D). There was also a slight decrease of MitoSOX fluorescence intensity in NGF-supported cells treated with FCCP or rotenone during the period of MitoSOX loading (intensity was $0.7 \pm 0.1-$ and $0.82 \pm 0.02$-fold of NGF control, respectively; $p<001$ by ANOVA). These findings are similar to those we reported for the effect of these compounds on $\mathrm{CM}-\mathrm{H}_{2}$ DCFDA fluorescence intensity in NGF-deprived cells (Kirkland et al., 2002b), further suggesting that the ROS detected by $\mathrm{CM}-\mathrm{H}_{2} \mathrm{DCFDA}$ lie downstream of dismutated $\mathrm{O}_{2}{ }^{--}$derived from the mitochondrial electron transport chain. It should be noted that MitoSOX targeting to mitochondria depends on mitochondrial membrane potential (see Materials and Methods) and that FCCP and rotenone both reduce this potential (Nicholls and Ferguson, 2002; Starkov et al., 2002). However, combined with the similar effects of these compounds on $\mathrm{CM}-\mathrm{H}_{2} \mathrm{DCFDA}$ intensity in NGF-deprived cells, which does not depend on mitochondrial membrane potential, the data strongly suggest a mitochondrial origin of the ROS. It should also be noted that a decrease in mitochondrial membrane potential that may occur during apoptosis could result in decreased MitoSOX loading into mitochondria and an underestimation of $\mathrm{O}_{2}{ }^{--}$levels in apoptotic cells. Experiments with the mitochondrial membrane potential probe tetramethylrhodamine methyl ester showed that NGF-deprived cells have mitochondria with reduced, but not absent, mitochondrial membrane potential (data not shown).

Figure $4 A$ shows that, in contrast to the rapid and potent suppressant effect that acute NGF readdition had on CM$\mathrm{H}_{2}$ DCFDA intensity in NGF-deprived neurons, acute reexposure of cells deprived of NGF for $24 \mathrm{~h}$ to NGF did not suppress MitoSOX fluorescence intensity in them. Neither NGFdeprived neurons nor neurons deprived of NGF and maintained in BAF-containing medium for this time showed any major decrease in MitoSOX intensity when NGF was added at the time of MitoSOX loading. To determine whether NGF readdition might suppress MitoSOX fluorescence over a slower time course, we deprived neurons of NGF and then added it back for periods ranging from $20 \mathrm{~min}$ to $6 \mathrm{~h}$. MitoSOX intensity increased slightly after acute NGF application and then declined to the basal level seen in neurons deprived of NGF for $24 \mathrm{~h}$. Intensity remained at about this level even after $6 \mathrm{~h}$ of re-exposure to NGF. MitoSOX intensity first decreased slightly in NGF-deprived BAF-saved neurons after re-exposure and then slowly returned to the intensity seen in these cells at $24 \mathrm{~h}$ after withdrawal (Fig. $4 \mathrm{~B}$ ). These findings suggest that mitochondria in sympathetic neurons deprived of NGF continue to generate elevated amounts of $\mathrm{O}_{2} \cdot$ - even after the readdition of NGF.

\section{Activation of glutathione redox cycling by NGF}

Published data suggest that the ROS detected by CM- $\mathrm{H}_{2}$ DCFDA in NGF-deprived rat and mouse sympathetic neurons lie downstream of dismutated mitochondrial $\mathrm{O}_{2} \cdot$ - (Kirkland and Franklin, 2001; Kirkland et al., 2002b). The findings presented here suggest that these ROS decrease after NGF readdition and that mitochondrial $\mathrm{O}_{2} \cdot$ - production does not decrease after NGF reexposure. The differential effects of NGF on CM- $\mathrm{H}_{2}$ DCFDA and MitoSOX intensities could be explained by NGF-mediated acti- 

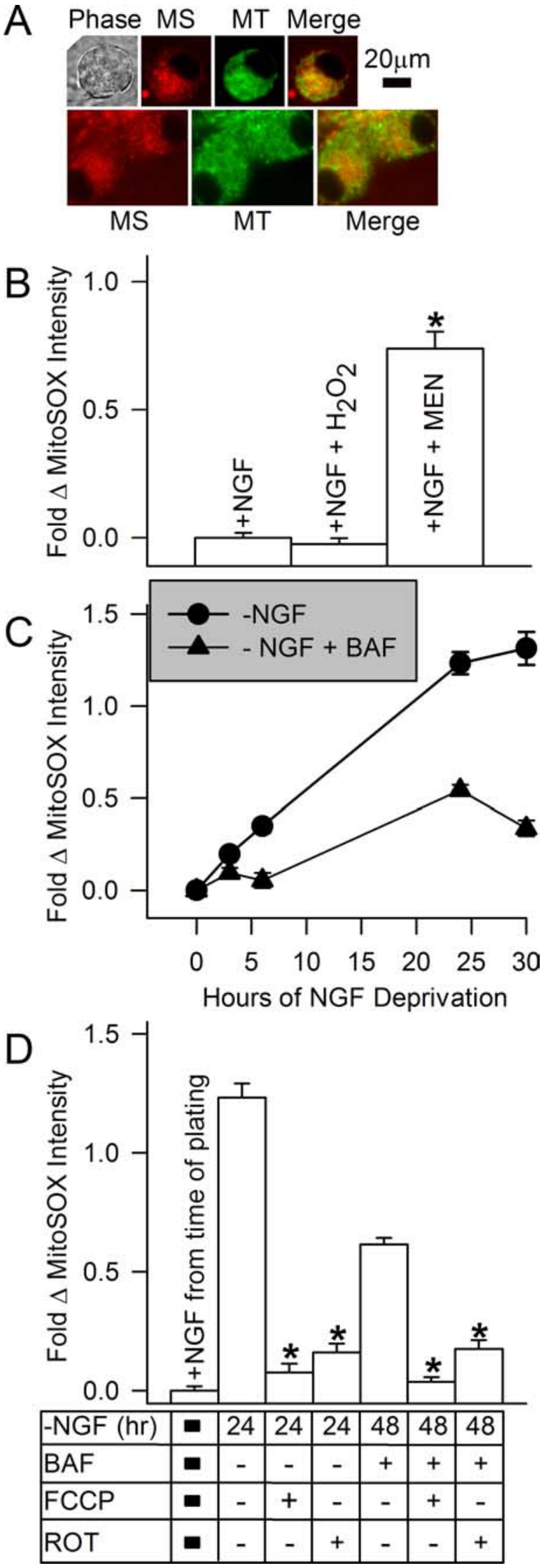

Figure 3. NGF withdrawal caused an increase in mitochondrial-derived $\mathrm{O}_{2} \div$. $A$, Phase and confocal micrographs of neurons double-labeled for $10 \mathrm{~min}$ with the mitochondrial dye MitoTracker Green (MT; $0.1 \mu \mathrm{M}$ ) (Johnson et al., 2007) and the mitochondrial $0_{2}{ }^{-}$indicator MitoSOX (MS; $2 \mu \mathrm{M}$ ). $\boldsymbol{B}$, Characterization of MitoSOX staining. Hydrogen peroxide had no effect vation of an antioxidant pathway that detoxifies the CM$\mathrm{H}_{2}$ DCFDA-detected ROS without affecting $\mathrm{O}_{2}-$ - production by mitochondria. We obtained evidence for such a mechanism in these cells through a serendipitous observation of differential rates of $\mathrm{CM}-\mathrm{H}_{2} \mathrm{DCFDA}$ photo-oxidation in NGF-replete and -deprived cells. Photo-oxidation is a process whereby intense light causes the production of free radical ROS (Hibbs, 2004). To obtain images of sympathetic neurons in culture with the confocal microscope, we typically hold laser power at $\sim 10 \%$ of maximum. This low power does not cause photo-oxidation, as detected by increased $\mathrm{CM}-\mathrm{H}_{2} \mathrm{DCFDA}$ intensity, in mouse sympathetic neurons even after multiple laser exposures (Kirkland et al., 2002b) (results not shown). However, exposure of these cells to $100 \%$ laser power did cause increased CM$\mathrm{H}_{2}$ DCFDA fluorescence intensity, indicating the production of ROS. In the process of recording $\mathrm{CM}-\mathrm{H}_{2} \mathrm{DCFDA}$ images, we noted that NGF-deprived neurons were much more sensitive to photo-oxidation by high laser power than were NGF-maintained cells (supplemental Fig. 2, available at www.jneurosci.org as supplemental material). This observation suggested that there were differences in the antioxidant capacities of NGF-deprived and -replete neurons.

The principal mechanism for removal of $\mathrm{H}_{2} \mathrm{O}_{2}$ from most cells, including neurons, is by conversion to $\mathrm{H}_{2} \mathrm{O}$ via the peroxidase-catalyzed oxidation of the tripeptide $\mathrm{GSH}$ by $\mathrm{H}_{2} \mathrm{O}_{2}$ (Halliwell and Gutteridge, 1999). The oxidized glutathione (GSSG) is then enzymatically reduced to GSH by glutathione reductase using reducing equivalents obtained from NADPH. To determine whether NGF was suppressing $\mathrm{H}_{2} \mathrm{O}_{2}$ or $\mathrm{H}_{2} \mathrm{O}_{2}$ generated ROS by activating the glutathione pathway in mouse sympathetic neurons, we attempted to assay the total amount of glutathione, glutathione peroxidase activity, and glutathione reductase activity in these cells. Unfortunately, we found that the amount of tissue obtainable from even large dissections of sympathetic ganglia was too little to determine the amount of glutathione or the activity of the enzymes using standard biochemical assays. To circumvent this problem, a single-cell assay using the membrane-permeant GSH probe MCB was used. MCB is nonfluorescent until bound to GSH in a reaction catalyzed by the enzyme glutathione $S$-transferase (Barhoumi et al., 1995; Decory et al., 2001). Figure $5 A$ shows that MCB stained brightly the somas of NGF-maintained neurons. An equivalent amount of $\mathrm{MCB}$ bound in both NGF-replete and -deprived cells, indicating that there were no differences in the levels of GSH in these neurons (Fig. $5 B$ ) ( $p>0.06$ by Mann-Whitney rank sum test). Therefore, total GSH concentrations were not altered by NGF deprivation, and NGF withdrawal did not modify the activity of glutathione $S$-transferase.

$\leftarrow$

on MitoSOX intensity in neurons maintained in NGF-containing medium. The $\mathrm{O}_{2}^{-}$generator menadione (Men; $80 \mu \mathrm{M}$ ) caused an increase in MitoSOX intensity, indicating selectivity for $\mathrm{O}_{2}$ over $\mathrm{H}_{2} \mathrm{O}_{2}$ in these cells $(p<0.001$ by ANOVA). Neurons were either maintained in culture medium containing NGF or deprived of NGF for $24 \mathrm{~h}$, treated with hydrogen peroxide ( $2 \mathrm{mM})$ in the presence of NGF for $30 \mathrm{~min}$, or treated with culture medium containing menadione for 30 $\mathrm{min}$ in the presence of NGF. MitoSOX was included in the media during the final $10 \mathrm{~min}$ of incubation. $n=130-292$ neurons. C, Time course of the increase in MitoSOX intensity (e.g., increased $\mathrm{O}_{2}{ }^{-}$) after NGF withdrawal. Cultures were maintained in NGF or deprived of NGF ( \pm $50 \mu \mathrm{m}$ BAF) for the indicated times and stained with MitoSOX (2 $\mu \mathrm{M})$ for $10 \mathrm{~min}$ before microscopy. $n=93-583$ neurons. $\boldsymbol{D}$, Rotenone $(10 \mu \mathrm{M})$, an inhibitor of electron transport through mitochondrial respiratory complex I, inhibited MitoSOX fluorescence, as did the mitochondrial uncoupler $\mathrm{FCCP}(1.6 \mu \mathrm{M})$. Both inhibitors were added only during the time of MitoSOX loading. $p<0.001$ for both $24 \mathrm{~h}$ and $48 \mathrm{~h}$ times by ANOVA indicated by stars. Statistical comparisons are made to NGF-deprived data within that time point. $n=133-305$ neurons. 


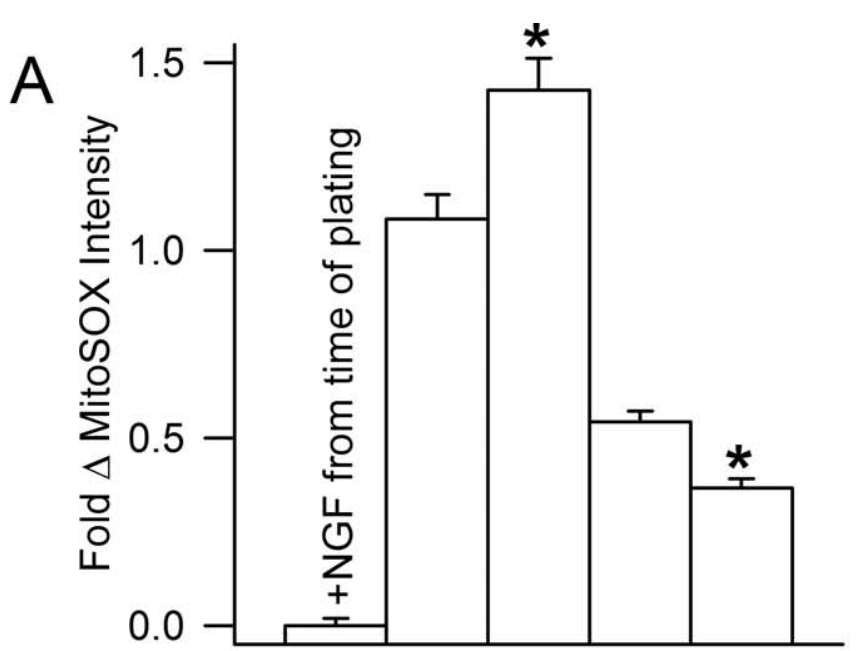

\begin{tabular}{|l|c|c|c|c|c|}
\hline- NGF $(\mathrm{hr})$ & - & 24 & 24 & 24 & 24 \\
\hline BAF & - & - & - & + & + \\
\hline +NGF (20 min) & - & - & + & - & + \\
\hline
\end{tabular}

B

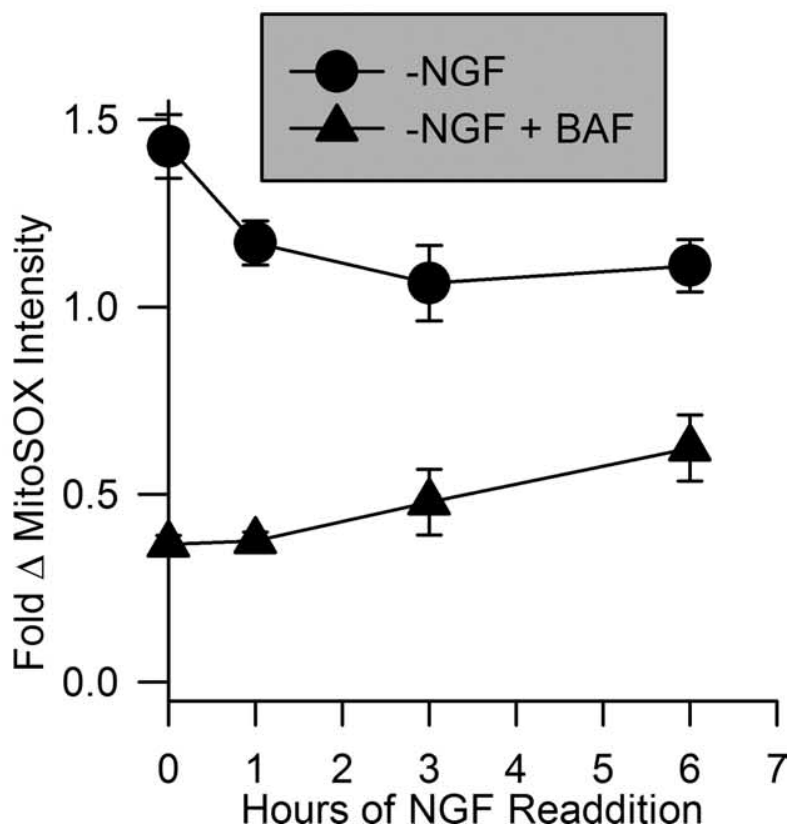

Figure 4. Superoxide levels were not suppressed after NGF was added back to NGF-deprived cultures. $A$, NGF readdition did not suppress increased $\mathrm{O}_{2}{ }^{-}$- in NGF-deprived cells. Cultures were exposed to MitoSOX ( $2 \mu \mathrm{m}$ ) for $10 \mathrm{~min}$ in the presence or absence of NGF ( $\pm \mathrm{BAF} ; 50 \mu \mathrm{m}$ ) as indicated, and then neurons were viewed by confocal microscopy. Cultures that had been deprived of NGF for $24 \mathrm{~h}$ and exposed to NGF again during MitoSOX loading exhibited a small increase in MitoSOX intensity compared with that in cells not re-exposed to NGF. Conversely, readdition of $N G F$ to cultures deprived of it for $24 \mathrm{~h}$ and exposed to BAF showed a small decrease in MitoSOX intensity on NGF readdition ( $p<0.001$ by Mann-Whitney rank sum test for both \pm BAF). $n=150-583$ neurons. $B$, MitoSOX intensity either continued to increase slightly after NGF readdition (with $50 \mu \mathrm{m}$ BAF) or declined slightly (without BAF). NGF was added back to NGF-deprived cultures $24 \mathrm{~h}$ after NGF withdrawal. At the indicated times after NGF readdition, cultures were exposed to MitoSOX $(2 \mu \mathrm{m})$ for $10 \mathrm{~min}$ in culture medium containing the appropriate treatments. Neurons were then viewed by confocal microscopy. $n=81-454$ neurons.

A similar steady-state concentration of GSH was maintained in NGF-replete and -deprived neurons (Fig. 5B). Therefore, the only conceivable means by which changes in the GSH pathway could account for the rapid ROS suppressant effects of NGF was by an increase in the rate of GSH turnover. Such a change in the rate of glutathione redox cycling could leave the GSH and GSH plus GSSG levels unaltered while increasing the rate of ROS detoxification. To explore this possibility, we used MCB in conjunction with $N, N^{\prime}$-Bis(2-chloroethyl)- $N$-nitrosourea (BCNU), a potent inhibitor of glutathione reductase activity in many cell types, including neurons (Babson and Reed, 1978; Starke and Farber, 1985; Tretter and Adam-Vizi, 2000). Treatment of cells with BCNU causes a loss of GSH at a rate determined by the rate of glutathione redox cycling. The rationale behind this assay was that, if NGF increased the rate of glutathione redox cycling, BCNU treatment should cause a more rapid loss of MCB staining in NGF-deprived cells re-exposed to NGF than in NGF-deprived neurons not treated with NGF. Exposure of cultures maintained in medium containing NGF from the time of plating to this concentration of BCNU had no effect on MCB staining even after $2 \mathrm{~h}$ of treatment (Fig. 5C). However, similar exposure of NGFdeprived cultures to BCNU caused a drop in MCB staining of $\sim 0.2$-fold by $0.5-2 \mathrm{~h}$ after the beginning of treatment $(p<0.001$ by ANOVA). Readdition of NGF and BCNU-containing medium to deprived cultures caused a much greater decrease in $\mathrm{MCB}$ intensity. By 1-2 h after the addition of BCNU and NGF, MCB intensity was $\sim 0.5$-fold lower than that in NGF-maintained cells (Fig. $5 C)(p<0.001$ by ANOVA). These data suggest that neurons maintained in NGF-containing medium from the time of plating have a very slow rate of glutathione redox cycling; otherwise, block of glutathione reductase by BCNU would have caused a decrease in MCB staining because of decreased amounts of GSH. This finding is consistent with the very low levels of ROS in these cells (i.e., rapid cycling did not occur because of the low ROS levels). The data suggest that NGF withdrawal increased the rate of production of $\mathrm{O}_{2} \cdot$ - by mitochondria (Figs. 4, 5) and, through dismutation, the amount of cellular $\mathrm{H}_{2} \mathrm{O}_{2}$. The increased loss of MCB staining in these cells when glutathione reductase was blocked likely reflects increased activity of the GSH pathway as the cells attempted to detoxify these ROS. That is, more GSH was being "used up" and not replenished because of the reductase block in the NGF-deprived neurons than in the NGF-maintained ones. Although the data suggest that activity of the GSH pathway in NGF-deprived cells increased, the increase was not enough to completely detoxify the elevated $\mathrm{H}_{2} \mathrm{O}_{2}$ lying downstream of increased production of $\mathrm{O}_{2}{ }^{--}$. Readdition of NGF to deprived cultures appeared to activate the GSH pathway as the loss of MCB staining was greatest in these cells when glutathione reductase was blocked. These data suggest that the rapid suppression of $\mathrm{H}_{2} \mathrm{O}_{2}$ and the other ROS detected by CM- $\mathrm{H}_{2}$ DCFDA was caused by activation of glutathione redox cycling by NGF. Consistent with this hypothesis, Figure $5 D$ shows that BCNU had no significant effect on $\mathrm{CM}-\mathrm{H}_{2}$ DCFDA intensity in NGF-maintained neurons ( $p>0.7$ by Mann-Whitney rank sum test) or in neurons deprived of NGF for $24 \mathrm{~h}$ ( $p>0.4$ by ANOVA). However, $\mathrm{BCNU}$ completely prevented readdition of NGF from suppressing the increased ROS detected by $\mathrm{CM}-\mathrm{H}_{2} \mathrm{DCFDA}$ in NGFdeprived cells ( $p>0.4$ by ANOVA). Chronically NGFsupported cells treated with BCNU $(5 \mu \mathrm{M})$ during the period of $\mathrm{CM}-\mathrm{H}_{2}$ DCFDA loading exhibited a greater increase in CM$\mathrm{H}_{2}$ DCFDA intensity than did untreated ones when photooxidized (10 scans at full laser power; $3.02 \pm 0.61$-fold increase for treated and $0.69 \pm 0.09$-fold for untreated; $p<0.001$ by Mann-Whitney rank sum test; $n=56-132$ ). A much greater increase in dye intensity occurred in cells deprived of NGF for $24 \mathrm{~h}$ (supplemental Fig. 2, available at www.jneurosci.org as supplemental material) when photo-oxidized by this paradigm, sug- 

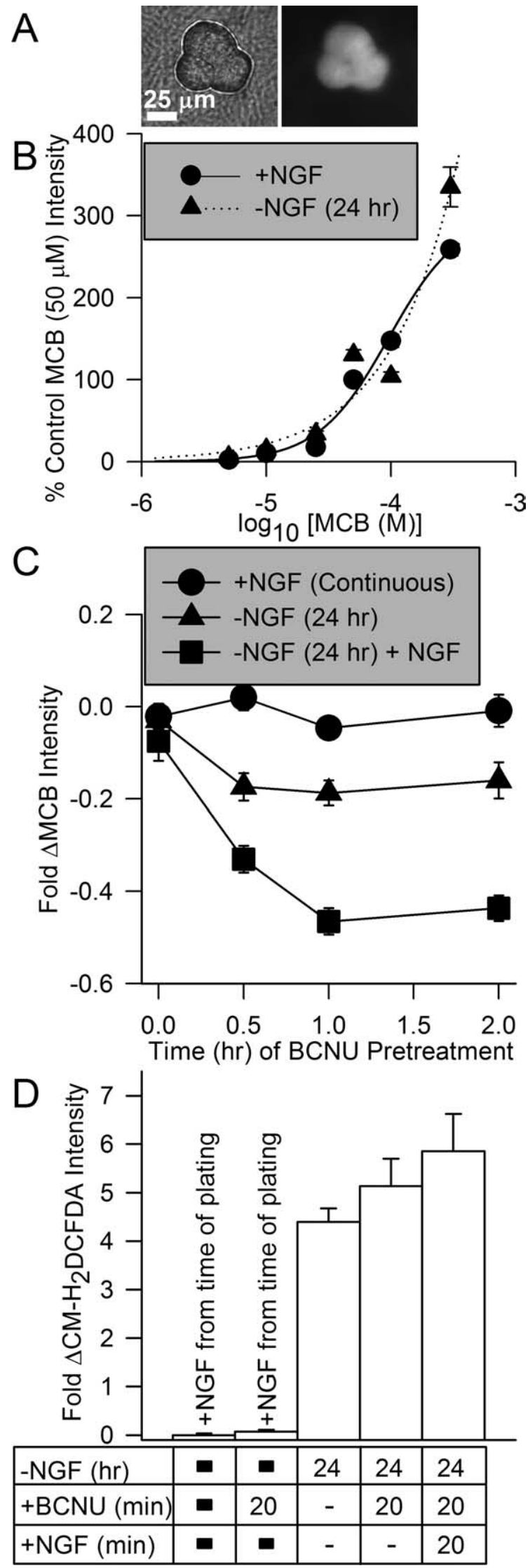

Figure 5. Activation of glutathione redox cycling was responsible for the rapid suppression of ROS by NGF. $\boldsymbol{A}$, Photomicrographs showing phase-contrast (left) and fluorescent (right) images of a cluster of three sympathetic neuronal somas stained with MCB (300 $\mu \mathrm{M})$. B, Staining of both NGF-replete and -deprived ( $24 \mathrm{~h}$ ) cells with MCB was identical. These data indicate gesting that sustained exposure to NGF may activate antioxidant mechanisms in addition to the glutathione pathway.

\section{Evidence that activation of glutathione redox cycling by NGF underlies NGF-mediated suppression of cytochrome $c$ redistribution}

The membrane-permeant antioxidants $N$-acetyl-L-cysteine and GSH ethyl ester inhibit the apoptotic death of NGF-deprived mouse sympathetic neurons by inhibiting release of cytochrome $c$ from mitochondria. Exposing these cells to a concentration of $\mathrm{H}_{2} \mathrm{O}_{2}$ that causes an intracellular pro-oxidant state similar to that caused by NGF withdrawal induces cytochrome $c$ redistribution (Kirkland et al., 2002b). These findings suggest a role for the elevated ROS levels in cytochrome $c$ redistribution in these cells. Approximately $50 \%$ of NGF-deprived sympathetic neurons are committed to death by $24 \mathrm{~h}$ after NGF withdrawal (Deckwerth and Johnson, 1993). That is, when NGF is added back to the cultures at this time, $\sim 50 \%$ of cells live while the others die by apoptosis. The block of death of the uncommitted cells by NGF readdition is secondary to an immediate block by NGF of any additional cytochrome $c$ release (Deshmukh and Johnson, 1998). The mechanism underlying this rapid block is unknown. Addition of GSH ethyl ester also immediately stops cytochrome $c$ release and prevents additional death from occurring (Kirkland and Franklin, 2003). The rapid activation by NGF of the GSH pathway for detoxifying $\mathrm{H}_{2} \mathrm{O}_{2}$ (Fig. 5) suggested the possibility that NGF also prevents release of cytochrome $c$ from mitochondria via an antioxidant mechanism. To explore this possibility, we treated NGF-deprived neurons with culture medium containing NGF. BCNU was included in the medium of some cultures to block GSH redox cycling. Cytochrome $c$ redistribution was determined by immunocytochemistry. As in many cells, the mitochondria in individual NGF-deprived sympathetic neurons appear to coordinately release cytochrome $c$ over a short period (Goldstein et al., 2000, 2005). This rapid release is followed by rapid loss of cytochrome $c$ from the cytoplasm, presumably by degradation (Deshmukh and Johnson, 1998; Neame et al., 1998; Kirkland and Franklin, 2001; Kirkland et al., 2002b). Sympathetic neurons with mitochondria retaining cytochrome $c$ exhibit intense, punctate immunocytochemical staining for cytochrome $c$, whereas those with cytochrome $c$-depleted mitochondria show only a faint, homogeneous staining. Figure $6 \mathrm{~A}$ shows how these criteria were used to score neurons as having retained or released cytochrome $c$ from mitochondria after NGF withdrawal. Figure $6 \mathrm{~B}$ shows the time course of cytochrome $c$ redistribution after NGF withdrawal. By $24 \mathrm{~h}$ after deprivation, $\sim 50 \%$ of cells had released cytochrome $c$ and $\sim 70 \%$ by $30 \mathrm{~h}$.

that the activity of glutathione $S$-transferase was not affected by NGF withdrawal. They also indicate that GSH concentration was similar in both conditions. Data was normalized to that of NGF-replete cells loaded with $50 \mu \mathrm{m}$ MCB. Curves are best least-squares fits of two parameter logistic equations to the data. $n=35-284$ neurons. $C$, Inhibition of glutathione reductase increased loss of GSH in NGF-deprived cells. Treatment of cultures with the glutathione reductase inhibitor BCNU $(5 \mu \mathrm{M})$ did not affect MCB staining $(300 \mu \mathrm{M})$ of neurons that had been maintained in media containing NGF. It did decrease MCB staining in NGF-deprived neurons, consistent with increased ROS in those cells and a more active glutathione pathway for detoxifying the ROS. Cultures deprived of NGF for $24 \mathrm{~h}$ and then exposed to NGF during the time of BCNU treatment exhibited greatly decreased MCB staining compared with control cells and cells deprived of NGF for $24 \mathrm{~h}$. Data were normalized to MCB intensity of NGF-maintained cultures not treated with BCNU. $n=26-107$ neurons. $\boldsymbol{D}$, Suppression of glutathione cycling by BCNU ( 5 $\mu \mathrm{M})$ prevented suppression of ROS by NGF readdition. Neurons deprived of NGF for $24 \mathrm{~h}$ were loaded with $\mathrm{CM}-\mathrm{H}_{2} \mathrm{DCFDA}$ in the presence of NGF or NGF and BCNU. $n=87-283$ neurons. 


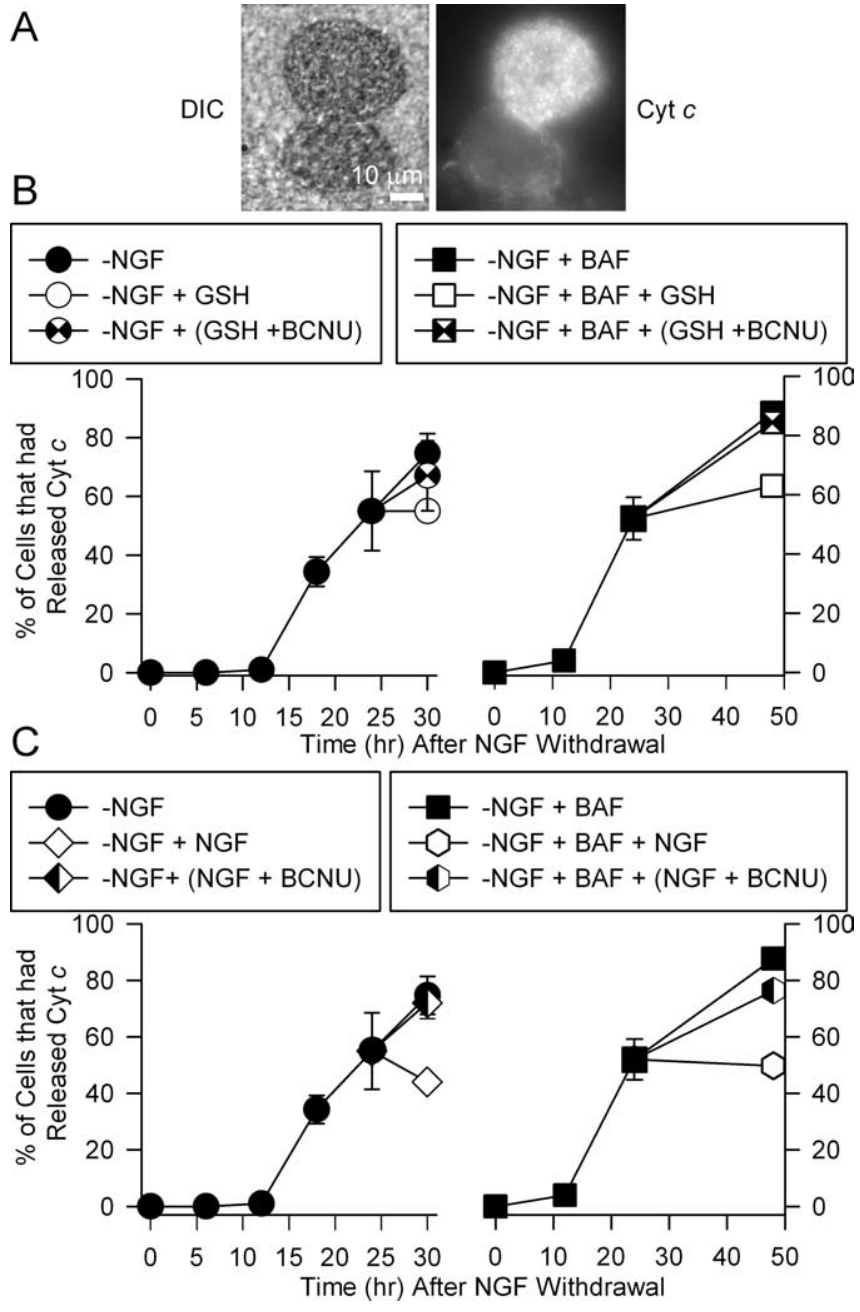

Figure 6. Readdition of NGF inhibited cytochrome c release in NGF-deprived cells by activating glutathione redox cycling. $\boldsymbol{A}$, Photomicrographs showing differential interference contrast (DIC; left) and fluorescence images of cytochrome c (Cyt c; right) immunostaining in neurons deprived of NGF for $24 \mathrm{~h}$. Note the lack of intense punctate staining in the bottom neuron, indicating that cytochrome chad been released into the cytoplasm where it was degraded. $\boldsymbol{B}, \boldsymbol{C}$, Addition of GSH ethyl ester ( $\boldsymbol{B} ; 8 \mathrm{~mm})$ or NGF $(\boldsymbol{C})$ inhibited additional release of cytochrome $c$. The inhibition of release caused by addition of GSH or NGF was blocked by the glutathione reductase inhibitor BCNU $(5 \mu \mathrm{m})$. Cultures were deprived of NGF in media either containing or lacking BAF $(50 \mu \mathrm{m})$. For some cultures, the indicated treatments were added $24 \mathrm{~h}$ after withdrawal. The cultures were then fixed and immunostained for cytochrome c at 30 or $48 \mathrm{~h}$ (only for + BAF cultures) after deprivation. The other cultures were fixed and immunostained at the indicated times. Neurons were scored as having retained cytochrome c in mitochondria or having released it as described previously (Kirkland and Franklin, 2001; Kirkland et al., 2002b). $n=3-6$ cultures with $\sim 50$ neurons counted for each.

As reported previously (Kirkland and Franklin, 2003), addition of either NGF or GSH ethyl ester to NGF-deprived cultures inhibited cytochrome $c$ redistribution. When either of these agents was added to cultures at $24 \mathrm{~h}$ after withdrawal, about the same percentage of cells exhibited punctate staining for cytochrome $c$ at $30 \mathrm{~h}$ after deprivation as at $24 \mathrm{~h}$. When BCNU was added at $24 \mathrm{~h}$ along with GSH ethyl ester to inhibit glutathione redox cycling, the block of cytochrome $c$ release was abrogated. Addition of BCNU along with NGF at this time also completely prevented NGF from blocking additional cytochrome $c$ release. Treatment of cultures maintained in NGF from the time of plating with BCNU ( $5 \mu \mathrm{M}$ for $24 \mathrm{~h}$ ) did not cause any cytochrome $c$ redistribution. One hundred percent of these neurons exhibited intense, punctate immunocytochemical staining for cytochrome $c(n=66$ neurons). It was not possible to follow cells deprived of NGF for longer than $30 \mathrm{~h}$, because most had died by later times. To determine the longer-term effects of treatment with these agents on cytochrome $c$ release, we maintained cells in medium containing BAF to prevent death. This treatment does not alter the time course of cytochrome $c$ redistribution (Kirkland et al., 2002b). Approximately 90\% of BAF-maintained cells had released cytochrome $c$ from mitochondria by $48 \mathrm{~h}$ after NGF withdrawal. Addition of GSH ethyl ester to the culture medium at $24 \mathrm{~h}$ after deprivation inhibited release. Treatment of these cells at $24 \mathrm{~h}$ after withdrawal with BCNU completely blocked the ability of GSH ethyl ester to inhibit cytochrome $c$ release in the subsequent $24 \mathrm{~h}$. Treatment of NGF-deprived, BAF-saved cultures at $24 \mathrm{~h}$ after withdrawal of NGF also inhibited additional cytochrome $c$ redistribution over the subsequent $24 \mathrm{~h}$ period. The ability of NGF to cause this block was prevented by including BCNU in the culture medium (Fig. 6C). Cells treated with BCNU appeared morphologically identical to those not treated with it (data not shown). These data suggest a role for activation of glutathione redox cycling by NGF in acute prevention of cytochrome $c$ redistribution by NGF readdition.

\section{Discussion}

Dugan et al. (1997) were among the first to report that withdrawing NGF from sympathetic neurons in cell culture causes increased levels of ROS in them. They also reported that readdition of NGF to NGF-deprived cultures rapidly suppresses these ROS. We conducted an investigation into the mechanism underlying this phenomenon. Additionally, we explored the role of ROS suppression by NGF in NGF-mediated block of cytochrome $c$ redistribution.

We first performed a confocal microscopic study of NGFdeprived cells loaded with the redox-sensitive dye CM$\mathrm{H}_{2}$ DCFDA. As reported previously (Kirkland and Franklin, 2001; Kirkland et al., 2002b), withdrawing NGF caused an increase in the fluorescence intensity of this dye, indicating that the cells had entered a pro-oxidant state. Maintaining neurons from the time of withdrawal in medium containing the broad-spectrum caspase inhibitor BAF suppressed $\sim 80 \%$ of this increase, suggesting involvement of caspases. Acute application of NGF to cultures deprived of it for $24 \mathrm{~h}$ also caused $\sim 80 \%$ suppression of the increase in dye intensity in BAF-saved cells deprived of NGF for this period. The suppression of dye intensity by NGF was not caused by reduction of the dye after it had become oxidized but was the result of an actual clearance of ROS from the cells. Pretreatment with NGF followed by subsequent withdrawal during the time of dye loading revealed that longer periods of NGF pretreatment resulted in longer delays before of ROS levels rose again subsequent to a second withdrawal. This finding indicates that the mechanism by which NGF readdition suppresses ROS becomes more persistent with longer periods of NGF exposure.

\section{Differential effects of NGF on the ROS detected by CM- $\mathrm{H}_{2}$ DCFDA and MitoSOX}

The data suggest that $\mathrm{CM}-\mathrm{H}_{2}$ DCFDA was oxidized in NGFdeprived neurons by $\mathrm{H}_{2} \mathrm{O}_{2}$-associated ROS lying downstream from dismutation of mitochondrial-derived $\mathrm{O}_{2}{ }^{--}$. The elevated levels of these ROS could result from increased mitochondrial production of $\mathrm{O}_{2}-$, by a reduction in the activity of enzymatic pathways for detoxifying them, or by both mechanisms. To determine whether changes in production or clearance of ROS were responsible for the suppression of $\mathrm{CM}-\mathrm{H}_{2} \mathrm{DCFDA}$ intensity when NGF was added to cultures of NGF-deprived neurons, we 
used MitoSOX, a new redox-sensitive dye that is targeted to mitochondria and shows selectivity for $\mathrm{O}_{2}{ }^{-{ }^{-}}$over other ROS (Robinson et al., 2006; Ross et al., 2005; Zhao et al., 2003, 2005). MitoSOX intensity increased after NGF withdrawal over the same time course as did CM- $\mathrm{H}_{2}$ DCFDA intensity. Similar to their effects on increased $\mathrm{CM}-\mathrm{H}_{2}$ DCFDA intensity after NGF withdrawal, BAF, FCCP, and the complex I inhibitor rotenone potently suppressed MitoSOX intensity. This finding suggests an increase in $\mathrm{O}_{2}{ }^{--}$production by mitochondria after NGF withdrawal and that, via dismutation, this $\mathrm{O}_{2}{ }^{--}$was responsible for the concurrent rise in the ROS detected by $\mathrm{CM}-\mathrm{H}_{2}$ DCFDA (Royall and Ischiropoulos, 1993).

Although readdition of NGF to NGF-deprived neurons rapidly attenuated CM- $\mathrm{H}_{2}$ DCFDA-detected ROS, there was no significant suppression of the ROS detected by MitoSOX. Therefore, NGF readdition did not suppress the $\mathrm{CM}-\mathrm{H}_{2} \mathrm{DCFDA}$-detected ROS by suppressing production of $\mathrm{O}_{2}{ }^{--}$by mitochondria. There are several possible ways that mitochondria could increase production of free radicals after NGF withdrawal. Caspases can increase mitochondrial ROS production in some cell lines by attacking mitochondrial respiratory complexes and increasing electron leakage from them (Ricci et al., 2003, 2004). Inhibition of both the MitoSOX- and CM- $\mathrm{H}_{2}$ DCFDA-detected ROS by BAF are consistent with a role for caspases in causing increased mitochondrial ROS production in NGF-deprived sympathetic neurons. It is likely that the continued elevation of MitoSOX fluorescence after hours of NGF readdition reflect, at least in part, increased $\mathrm{O}_{2}{ }^{--}$production by caspase-damaged respiratory complexes. Another means by which NGF withdrawal may lead to increased mitochondrial ROS production is via loss of cytochrome $c$ from the electron transport chain (Starkov et al., 2002). We found that depletion of cytochrome $c$ from the chain persisted even after $2 \mathrm{~h}$ of NGF readdition and could account for some of the ROS produced. All ROS in NGF-deprived mouse sympathetic neurons lie downstream of Bax (Kirkland et al., $2002 \mathrm{~b}$ ). Much of the pro-oxidant effect of Bax is likely caused by Bax-induced release of cytochrome $c$, which both activates caspases and depletes the electron transport chain of cytochrome c. A final mechanism by which NGF deprivation might increase mitochondrial ROS production is by a direct pro-oxidant effect of BAX on mitochondria that is independent of its effects on caspases and cytochrome $c$ depletion. We previously presented evidence for such an effect of Bax in NGF-deprived mouse sympathetic neurons (Kirkland et al., 2002b).

\section{Activation of glutathione redox cycling by NGF}

Regardless of the mechanism by which mitochondria increase ROS production after NGF withdrawal, it is clear from the MitoSOX finding that suppression of mitochondria-produced $\mathrm{O}_{2}$ by NGF readdition did not occur. Therefore, the rapid suppression of CM- $\mathrm{H}_{2}$ DCFDA-detected ROS has to lie downstream of mitochondrial $\mathrm{O}_{2}{ }^{--}$production. This finding suggests that NGF activates an anti-oxidant pathway that detoxifies $\mathrm{H}_{2} \mathrm{O}_{2}$ and other ROS detected by this dye. This hypothesis was lent credence by the finding that NGF-deprived neurons were much more susceptible to laser photo-oxidation, as detected by $\mathrm{CM}-\mathrm{H}_{2} \mathrm{DCFDA}$, than NGF-replete neurons or neurons that had been deprived of NGF before its readdition. The most likely antioxidant mechanism underlying suppression of these ROS by NGF is the glutathione redox cycling pathway. We used an in-cell assay for glutathione cycling based on the GSH-sensitive dye MCB and the glutathione reductase inhibitor BCNU. This assay revealed that glutathione redox cycling was very slow in neurons maintained

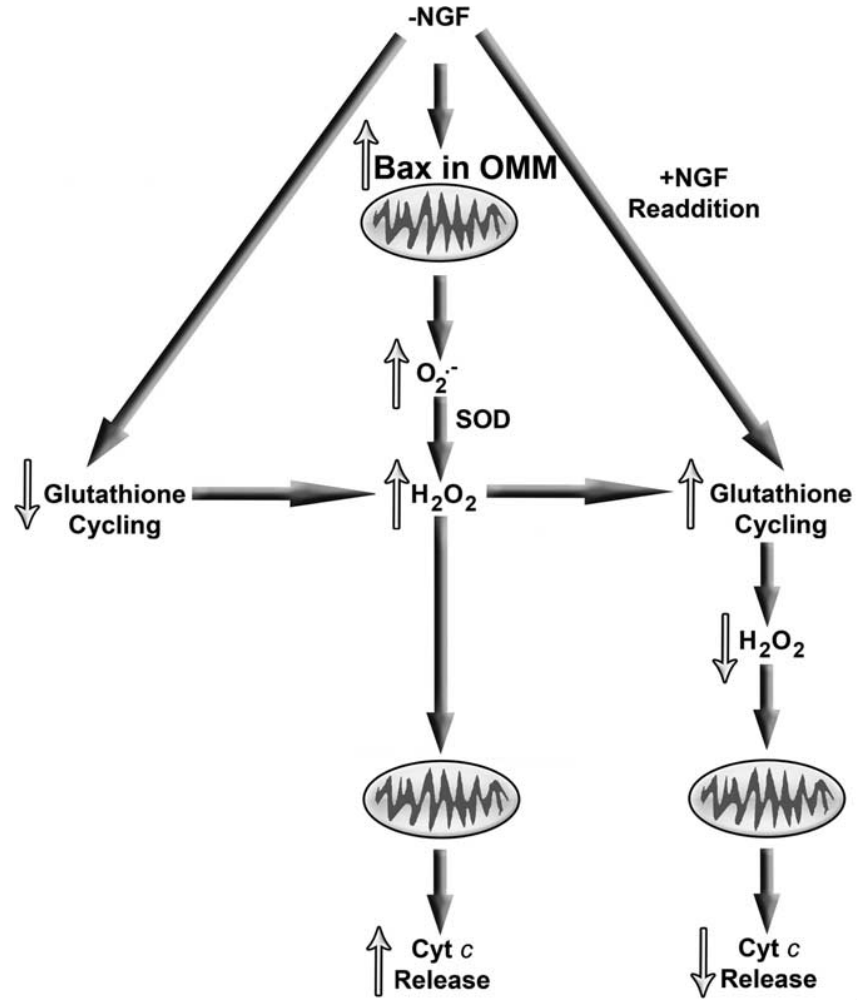

Figure 7. Summary of mitochondrial events in NGF-deprived mouse sympathetic neurons suggested by published reports and by findings presented in this study. Withdrawal of NGF causes Bax to bind tightly to the mitochondrial outer membrane in these cells. This binding causes increased mitochondrial $\mathrm{O}_{2}{ }^{-}$production. The $\mathrm{O}_{2}{ }^{-}$is dismutated to $\mathrm{H}_{2} \mathrm{O}_{2}$ in a reaction catalyzed by superoxide dismutase (SOD). The rate of glutathione redox cycling after NGF withdrawal is not great enough to clear all of the resulting $\mathrm{H}_{2} \mathrm{O}_{2}$ from neurons and leads to globally elevated levels of $\mathrm{H}_{2} \mathrm{O}_{2}$. The elevated $\mathrm{H}_{2} \mathrm{O}_{2}$ induces mitochondria to release cytochrome $C$ (Cyt c) from the mitochondrial intermembrane space into the cytoplasm where it activates the intrinsic apoptotic cascade. Readdition of NGF to deprived cells rapidly increases the rate of glutathione cycling with the result that $\mathrm{H}_{2} \mathrm{O}_{2}$ is swiftly converted to $\mathrm{H}_{2} \mathrm{O}$, and $\mathrm{H}_{2} \mathrm{O}_{2}$-induced cytochrome c release and apoptosis are acutely inhibited. This NGF readdition does not affect Baxdependent $\mathrm{O}_{2} \cdot-$ production by mitochondria.

from the time of plating in media containing NGF. It was more rapid in cells deprived of NGF for $24 \mathrm{~h}$, likely because of the increased level of ROS in them. Readdition of NGF to these cultures significantly increased GSH cycling in them. Inhibition of cycling with BCNU blocked the ability of NGF to suppress ROS. These data indicate that NGF can rapidly activate the glutathione redox cycling pathway and suggest that this is the mechanism underlying its ability to rapidly suppress $\mathrm{H}_{2} \mathrm{O}_{2}$-associated ROS.

\section{Role of ROS in NGF-mediated suppression of cytochrome $c$ redistribution}

Suppression of ROS in NGF-deprived neurons by antioxidants inhibits cytochrome $c$ redistribution and death. Treatment with a pro-oxidant that causes an increase in ROS similar to that seen in NGF-deprived cells induces cytochrome $c$ release (Kirkland et al., 2002b). The exact mechanism by which Bax causes cytochrome $c$ to exit mitochondria during apoptosis remains unclear (Chipuk et al., 2006; Green, 2006). There is evidence that Bax can form lipidic pores in the outer mitochondrial membrane that are large enough for cytochrome $c$ and other proteins to pass through (Kuwana et al., 2002). It appears that much of the cytochrome $c$ in the mitochondrial intermembrane space is actually bound to cardiolipin in the inner mitochondrial membrane and that peroxi- 
dation of this lipid may be necessary for cytochrome $c$ redistribution (Ott et al., 2002; Iverson et al., 2004). In this scenario, Bax induces pores in the outer membrane, but the cytochrome $c$ exits only when the association with cardiolipin is disrupted by lipid peroxidation. Such peroxidation occurs in NGF-deprived sympathetic neurons (Kirkland et al., 2002a), suggesting that the ROS may be causing cytochrome $c$ exit in this way. However, an artificially-induced pro-oxidant state similar to that seen in NGFdeprived neurons can cause cytochrome $c$ to exit the mitochondria of these cells even when they do not express Bax (Kirkland et al., 2002b). Therefore, it seems that Bax is dispensable for release in these cells, but the ROS are not.

Figure 7A summarizes ROS-related events in NGF-deprived sympathetic neurons suggested by published reports and by the findings presented in this study. After NGF withdrawal, Bax translocates to the outer mitochondrial membrane where it causes increased production of $\mathrm{O}_{2} \cdot-$. Superoxide dismutase catalyzes the conversion of the $\mathrm{O}_{2}{ }^{--}$to $\mathrm{H}_{2} \mathrm{O}_{2}$ that then causes cytochrome $c$ to be released. After return of NGF to deprived cells (Fig. $7 \mathrm{~B}$ ), glutathione cycling increases, reducing $\mathrm{H}_{2} \mathrm{O}_{2}$ levels and blocking cytochrome $c$ redistribution.

\section{References}

Babson JR, Reed DJ (1978) Inactivation of glutathione reductase by 2-chloroethyl nitrosourea-derived isocyanates. Biochem Biophys Res Commun 83:754-762.

Barhoumi R, Bailey RH, Burghardt RC (1995) Kinetic analysis of glutathione in anchored cells with monochlorobimane. Cytometry 19:226-234.

Cai J, Jones DP (1998) Superoxide in apoptosis: mitochondrial generation triggered by cytochrome $\mathrm{c}$ loss. J Biol Chem 273: 11401-11404.

Chipuk JE, Bouchier-Hayes L, Green DR (2006) Mitochondrial outer membrane permeabilization during apoptosis: the innocent bystander scenario. Cell Death Differ 13:1396-1402.

Danial NN, Korsmeyer SJ (2004) Cell death: critical control points. Cell 116:205-219.

Deckwerth TL, Johnson Jr EM (1993) Temporal analysis of events associated with programmed cell death (apoptosis) of sympathetic neurons deprived of nerve growth factor. J Cell Biol 123:1207-1222.

Deckwerth TL, Elliot JL, Knudson CM, Johnson Jr EM, Snider WD, Korsmeyer SJ (1996) Bax is required for neuronal death after trophic factor deprivation and during development. Neuron 17:401-411.

Decory HH, Piech-Dumas KM, Sheu S, Federoff HJ, Anders MW (2001) Efflux of glutathione conjugate of monochlorobimane from striatal and cortical neurons. Drug Metab Dispos 29:1256-1262.

Deshmukh M, Johnson Jr EM (1998) Evidence of a novel event during neuronal death: development of competence-to-die in response to cytoplasmic cytochrome c. Neuron 21:695-705.

Deshmukh M, Vasilakos J, Deckwerth TL, Lampe PA, Shivers BD, Johnson Jr EM (1996) Genetic and metabolic status of NGF-deprived sympathetic neurons saved by an inhibitor of ICE-family proteases. J Cell Biol 135:1341-1354.

Deshmukh M, Kuida K, Johnson Jr EM (2000) Caspase inhibition extends the commitment to neuronal death beyond cytochrome $c$ release to the point of mitochondrial depolarization. J Cell Biol 150:131-144.

Du C, Fang M, Li Y, Li L, Wang X (2000) Smac, a mitochondrial protein that promotes cytochrome-c dependent caspase activation by eliminating IAP inhibition. Cell 102:33-42.

Dugan LL, Creedon DJ, Johnson Jr EM, Holtzman DM (1997) Rapid suppression of free radical formation by nerve growth factor involves the mitogen-activated protein kinase pathway. Proc Natl Acad Sci USA 94:4086-4091.

Fernandez-Checa JC, Kaplowitz NC (1990) The use of monochlorobimane to determine the hepatic GSH levels and synthesis. Anal Biochem 190: 212-219.

Franklin JL, Johnson Jr EM (1998) Control of neuronal size homeostasis by trophic factor-mediated coupling of protein degradation to protein synthesis. J Cell Biol 142:1313-1324.

Franklin JL, Sanz-Rodriguez C, Juhasz A, Deckwerth TL, Johnson Jr EM (1995) Chronic depolarization prevents programmed death of sympa- thetic neurons in vitro but does not support growth: requirement for $\mathrm{Ca}^{2+}$ influx but not Trk activation. J Neurosci 15:643-664.

Goldstein JC, Waterhouse NJ, Juin P, Evans GI, Green DR (2000) The coordinate release of cytochrome $c$ during apoptosis is rapid, complete, and kinetically invariant. Nat Cell Biol 2:156-162.

Goldstein JC, Muñoz-Pinedo C, Ricci J-E, Adams SR, Kelekar A, Schuler M, Tsien RY, Green DR (2005) Cytochrome $c$ is released in a single step during apoptosis. Cell Death Differ 12:453-462.

Green DR (2006) At the gates of death. Cancer Cell 9:328-330.

Greenlund LJS, Deckwerth TL, Johnson Jr EM (1995) Superoxide dismutase delays neuronal apoptosis: a role for reactive oxygen species in programmed neuronal death. Neuron 14:303-315.

Gutierrez PL (2000) The metabolism of quinone-containing alkylating agents: free radical production and measurement. Front Biosci 5:d629-628.

Halliwell B, Gutteridge JMC (1999) Free radicals in biology and medicine, Ed 3. Oxford: Oxford UP.

Hibbs AR (2004) Confocal microscopy for biologists. New York: Springer. Iverson SL, Enoksson M, Gogvadze V, Ott M, Orrenius S (2004) Cardiolipin is not required for bax-mediated cytochrome $c$ release from yeast mitochondria. J Biol Chem 279:1100-1107.

Johnson LI, Jekabsons MB, Wang A, Polster BM, Nicholls DG (2007) "Mild uncoupling" does not decrease mitochondrial superoxide levels in cultured cerebellar granule neurons but decreases spare respiratory capacity and increases toxicity to glutamate and oxidative stress. J Neurochem 101:1619-1631.

Kirkland RA, Franklin JL (2001) Evidence for redox regulation of cytochrome $\mathrm{c}$ release during programmed neuronal death: antioxidant effects of protein synthesis and caspase inhibition. J Neurosci 21:1949-1963.

Kirkland RA, Franklin JL (2003) Bax, reactive oxygen, and cytochrome $c$ release in neuronal apoptosis. Antioxid Redox Signal 5:589-596.

Kirkland RA, Adibhatla RM, Hatcher JF, Franklin JL (2002a) Loss of cardiolipin and mitochondria during programmed neuronal death: evidence of a role for lipid peroxidation and autophagy. Neuroscience 115:587-602.

Kirkland RA, Windelborn JA, Kasprzak JM, Franklin JL (2002b) A Baxinduced pro-oxidant state is critical for cytochrome $c$ release during programmed neuronal death. J Neurosci 22:6480-6490.

Kuwana T, Mackey MR, Perkins G, Ellisman MH, Latterich M, Schneiter R, Green DR, Newmeyer DD (2002) Bid, bax, and lipids cooperate to form supramolecular openings in outer mitochondrial membrane. Cell 111:331-342.

Li LY, Luo X, Wang X (2001) Endonuclease G is an apoptotic DNAse when released from mitochondria. Nature 412:95-99.

Li P, Nijhawan D, Budihardjo I, Srinivasula SM, Ahmad M, Alnemri ES, Wang X (1997) Cytochrome c and dATP-dependent formation of Apaf$1 /$ caspase- 9 complex initiates an apoptotic protease cascade. Cell 91:479-489.

Liu X, Kim CN, Yang J, Jemmerson R, Wang X (1996) Induction of apoptotic program in cell-free extracts: requirement for dATP and cytochrome c. Cell 86:147-157.

Martin DP, Schmidt RE, DiStefano PS, Lowry OH, Carter JG, Johnson Jr EM (1988) Inhibitors of protein synthesis and RNA synthesis prevent neuronal death caused by nerve growth factor deprivation. J Cell Biol 106:829-844.

Neame SJ, Rubin LL, Philpott KL (1998) Blocking cytochrome c activity within intact neurons inhibits apoptosis. J Cell Biol 142:1583-1593.

Nicholls DG, Budd SL (2000) Mitochondria and neuronal survival. Physiol Rev 80:315-360.

Nicholls DG, Ferguson SJ (2002) Bioenergetics 3. London: Academic.

Nicholls DG, Ward MW (2000) Mitochondrial membrane potential and cell death: mortality and millivolts. Trends Neurosci 23:166-174.

Oppenheim RW (1991) Cell death during development of the nervous system. Annu Rev Neurosci 14:453-501.

Ott M, Robertson JD, Gogvadze V, Zhivotovsky B, Orrenius S (2002) Cytochrome $c$ release from mitochondria proceeds by a two-step process. Proc Natl Acad Sci USA 99:1259-1263.

Putcha GV, Deshmukh M, Johnson Jr EM (1999) Bax translocation is a critical event in neuronal apoptosis: regulation by neuroprotectants, Bcl-2, and caspases. J Neurosci 19:7476-7485.

Putcha GV, Deshmukh M, Johnson Jr EM (2000) Inhibition of apoptotic 
signaling cascades causes loss of trophic factor dependence during neuronal maturation. J Cell Biol 149:1011-1018.

Ricci JE, Gottlieb RA, Green DR (2003) Caspase-mediated loss of mitochondrial function and generation of reactive oxygen species during apoptosis. J Cell Biol 160:65-75.

Ricci JE, Munoz-Pinedo C, Fitzgerald P, Bailly-Maitre B, Perkins GA, Yadava N, Scheffler IE, Ellisman MH, Green DR (2004) Disruption of mitochondrial function during apoptosis is mediated by caspase cleavage of the p75 subunit of complex I of the electron transport chain. Cell 117:773-786.

Robinson KM, Janes MS, Pehar M, Monette JS, Ross MF, Hagen TM, Murphy MP, Beckman JS (2006) Selective fluorescent imaging of superoxide in vivo using ethidium-based probes. Proc Natl Acad Sci USA 103:15038-15043.

Ross MF, Kelso GF, Blaikie FH, James AM, Cochemé1 HM, Filipovska A, Da Ros T, Hurd TR, Smith RAJ, Murphy MP (2005) Lipophilic triphenylphosphonium cations as tools in mitochondrial bioenergetics and free radical biology. Biochem (Moscow) 70:222-230.

Royall JA, Ischiropoulos H (1993) Evaluation of 2', 7'-dichlorofluorescin and dihydrorhodamine 123 as fluorescent probes for intracellular $\mathrm{H}_{2} \mathrm{O}_{2}$ in cultured endothelial cells. Arch Biochem Biophys 302:348-355.

Starke PE, Farber JL (1985) Endogenous defenses against the cytotoxicity of hydrogen peroxide in cultured rat hepatocytes. J Biol Chem 260:86-92.

Starkov AA, Polster BM, Fiskum G (2002) Regulation of hydrogen peroxide production by brain mitochondria by calcium and Bax. J Neurochem 83:220-228.

Susin SA, Lorenzo HK, Zamzami N, Marzo I, Snow BE, Brothers GM, Mangion J, Jacotot E, Costantini P, Loeffler M, Larochette N, Goodlett DR, Aebersold R, Siderovski DP, Penninger JM, Kroemer G (1999) Molecu- lar characterization of mitochondrial apoptosis-inducing factor. Nature 397:441-446.

Tan S, Sagara Y, Liu Y, Maher P, Schubert D (1998) The regulation of reactive oxygen species production during programmed cell death. J Cell Biol 141:1423-1432.

Thor H, Smith MT, Hartzell P, Bellomo G, Jewell SA, Orrenius S (1982) The metabolism of menadione (2-methyl-1,4-naphthoquinone) by isolated hepatocytes. J Biol Chem 257:12419-12425.

Tretter L, Adam-Vizi V (2000) Inhibition of krebs cycle enzymes by hydrogen peroxide: key role of $\alpha$-ketoglutarate dehydrogenase in limiting NADH production under oxidative stress. J Neurosci 20:8972-8979.

Turrens JF (1997) Superoxide production by the mitochondrial respiratory chain. Bioscience Rep 17:3-8.

Xie L, Johnson RS, Freeman RS (2005) Inhibition of NGF deprivationinduced death by low oxygen involves suppression of $\mathrm{BIM}_{\mathrm{EL}}$ and activation of HIF-1. J Cell Biol 168:911-920.

Yuan J, Yanker BA (2001) Apoptosis in the nervous system. Nature 407:802-809.

Zhao H, Kalivendi S, Zhang H, Joseph J, Nithipatikom K, Vasquez-Vivar J, Kalyanaraman B (2003) Superoxide reacts with hydroethidine but forms a fluorescent product that is distinctly different from ethidium: potential implications in intracellular fluorescence detection of superoxide. Free Radic Biol Med 34:1359-1368.

Zhao H, Joseph J, Fales HM, Sokoloski EA, Levine RL, Vasquez-Vivar J, Kalyanaraman B (2005) Detection and characterization of the product of hydroethidine and intracellular superoxide by HPLC and limitations of fluorescence. Proc Natl Acad Sci USA 102:5727-5732.

Zou H, Henzel WJ, Liu X, Lutschg A, Wang X (1997) Apaf-1, a human protein homologous to $C$. elegans Ced-4, participates in cytochrome c-dependent activation of caspase-3. Cell 90:405-413. 